\title{
Gastric emptying of two radiolabelled antacids
}

\author{
J Monés, I Carrió, M Roca, M Estorch, R Calabuig, S Sainz, C Martinez-Duncker, F Vilardell
}

\begin{abstract}
The rate of gastric emptying of two antacids, magaldrate and Maalox, was investigated using scintigraphy. Successful labelling of the antacids was carried out with ${ }^{99 m} \mathrm{Tc}$. The stability of the ${ }^{9 \mathrm{~m} m} \mathrm{Tc}$-labelled antacids was satisfactory and there was no difference in antacid capacity between the labelled and unlabelled antacids. The studies were carried out on 15 healthy male volunteers. After an eight hour fast each subject ingested a standardised meal of $95.7 \mathrm{MJ}$ (400 kcal). One hour later $10 \mathrm{ml}$ of one of the two antacids previously labelled with ${ }^{9 m} \mathrm{Tc}$ was administered. Serial detection by anterior and posterior projection of the amount of antacid retained in the stomach was performed to determine gastric emptying of antacid. One week later the study was repeated under the same conditions with the other antacid also labelled with ${ }^{{ }^{9} \mathrm{~m}} \mathrm{Tc}$. The mean (SD) percentages of antacid retained in the stomach fit a linear model with a t1/2 of $\mathbf{8 6 . 6}$ $(15.3)$ minutes for magaldrate and $52.3(5.2)$ minutes for Maalox $(\mathbf{p}<0.01)$. When the mean percentages of retention at six time intervals were compared for both antacids, it was found that Maalox emptied much faster $(p<0.01$ at 15 and 30 minutes, $p<0.02$ at $45,60,75$, and 90 minutes).
\end{abstract}

The effectiveness of antacids in healing duodenal ulcer is well documented..$^{1-5}$ Until a few years ago this was thought to be directly related to the complete neutralisation of gastric $\mathrm{pH},{ }^{6}$ which required high dosages $(210 \mathrm{ml} /$ day capable of neutralising 800-1000 mmol HCl/day). More recent studies have shown that lower dosages of antacids are also therapeutically effective, ${ }^{7-10}$ perhaps because these drugs seem to stimulate the protection and repair of the gastric mucosal membrane in experiments carried out in both animals ${ }^{11}{ }^{12}$ and humans. ${ }^{13}$ It has been shown that the aluminium in antacids stimulates protection of the gastric mucosa through dependent as well as independent mechanisms of prostaglandin release. ${ }^{14} 15$

The effectiveness of antacids in neutralising gastric acid and improving mucosal defence factors depends on their chemical composition, the time of ingestion, the secretory capacity, the patient's rate of gastric emptying, and the rate of gastric emptying of antacids. ${ }^{16-18}$

The aim of the study was to assess the gastric emptying of two different antacids under physiological conditionsusing a scintigraphic technique.

\section{Methods}

Studies were carried out on 15 healthy male volunteers, mean (SD) age 35(6) years, after they gave informed consent.

\section{ANTACIDS}

Commercial doses of antacids (10 ml samples) were used. Magaldrate (Boehringer-Mannheim Laboratories) is a chemical combination of aluminium hydroxide and magnesium hydroxide. A comparison of the $x$ ray spacing of the magaldrate dosage form and hydrotalcite clearly shows that magaldrate has a hydrotalcitelike structure, ${ }^{19}$ with sulphate as the major interlayer anion and carbonate present in the interlayer space. A $10 \mathrm{ml}$ sample containing 800 mg magaldrate has a theoretical neutralisation capacity of $26.20 \mathrm{mEq} / \mathrm{HCl} .^{20}$ Maalox (Rorer Laboratories) is an aluminium hydroxidemagnesium hydroxide gel in suspension. A $10 \mathrm{ml}$ sample contains $450 \mathrm{mg}$ aluminium hydroxide and $400 \mathrm{mg}$ magnesium hydroxide with a theoretical neutralisation capacity of $26.00 \mathrm{mEq} / \mathrm{HCl} .^{20}$

\section{LABELLING}

Antacids were labelled with ${ }^{99 m} \mathrm{Tc}$ using a pyrophosphate bridge as follows:

(a) Preparation of ${ }^{99 m} T c$-pyrophosphate: $30 \mathrm{mCi}$ ${ }^{99 m}$ Tc-pertechnetate with a total volume of $5 \mathrm{ml}$ was added to a vial containing $15 \mathrm{ml}$ sodium pyrophosphate $\times \mathrm{H}_{2} \mathrm{O}$ and $2 \mathrm{mg} \mathrm{SnCl}_{2} \times \mathrm{H}_{2} \mathrm{O}$ in lyophilised form (Pyrotec, Sorin). This volume was adjusted with $0.15 \mathrm{M} \mathrm{NaCl}$. After gentle mixing the solution was allowed to stand at room temperature for at least 5 minutes.

(b) Preparation of the ${ }^{99 m}$ Tc-pyrophosphate antacid: $10 \mathrm{ml}$ of the antacid, magaldrate or Maalox, was put in a glass vial; $0.5 \mathrm{ml}$ of the ${ }^{99 m}$ Tc-pyrophosphate was added drop by drop to the antacid. The resulting suspension was gently mixed with a $1 \mathrm{ml}$ pipette and left to stand at room temperature for 5 minutes. After labelling we found that over $98 \%$ of the ${ }^{99 \mathrm{~m}} \mathrm{Tc}$ was finally in ${ }^{99 \mathrm{~m}} \mathrm{Tc}$-pyrophosphate antacid form.

The stability of the ${ }^{99 m} \mathrm{Tc}$-pyrophosphate antacids in gastric juice was tested as follows: $0.2 \mathrm{ml}$ of labelled antacid was added to $2 \mathrm{ml}$ of gastric juice adjusted to a $\mathrm{pH}$ of 1.5 to $\mathrm{pH} 7$ and incubated at $37^{\circ} \mathrm{C}$ for $10,30,60$, and 120 minutes. After incubation the ${ }^{99 \mathrm{~m}} \mathrm{Tc}$-pyrophosphate antacids present were measured by centrifuging at $1000 \mathrm{~g}$ for 10 minutes. The solid phase in the bottom was separated from the liquid supernatant and both counted in a gammacounter.

The antacid capacity of the labelled antacids was compared with that of the unlabelled antacids as follows: $2 \mathrm{ml}$ of antacid (unlabelled or labelled) was added by continuous stirring to a flask containing $10 \mathrm{ml}$ of $0.4 \mathrm{M} \mathrm{HCl}$ and $10 \mathrm{ml}$ of $0.15 \mathrm{M} \mathrm{NaCl}$. The $\mathrm{pH}$ was measured with a $\mathrm{pH}$ meter and the time necessary to reach $\mathrm{pH} 3 \cdot 4$, 3.5 , and 3.6 recorded. To ascertain whether the labelling of the antacids would alter protein binding, the following experiment was done: to $0.5 \mathrm{ml}$ of antacid $10 \mu \mathrm{l}$ of ${ }^{125} \mathrm{I}$-HSA $(2 \mu \mathrm{g}$ human 
TABLE I Percentage of radioactivity bound to magaldrate and Maalox in contact gastric juice at $\mathrm{pH} 1 \cdot 5-7$ at different times $(n=3 ;$ mean $(S D))$

\begin{tabular}{clllllll}
\hline \multicolumn{7}{c}{$p H$} \\
\cline { 2 - 7 } Time $($ min $)$ & $1 \cdot 5$ & 2 & 3 & 4 & 5 & 6 & 7 \\
\hline Magaldrate: & & & & & & & \\
10 & $97 \cdot 7(0 \cdot 1)$ & $97 \cdot 5(0 \cdot 2)$ & $97 \cdot 4(0 \cdot 2)$ & $97 \cdot 9(0 \cdot 1)$ & $97 \cdot 8(0 \cdot 2)$ & $98 \cdot 1(0 \cdot 2)$ & $98 \cdot 4(0 \cdot 1)$ \\
30 & $97 \cdot 7(0 \cdot 2)$ & $97 \cdot 2(0 \cdot 2)$ & $97 \cdot 2(0 \cdot 2)$ & $97 \cdot 7(0 \cdot 1)$ & $97 \cdot 6(0 \cdot 1)$ & $98 \cdot 0(0 \cdot 2)$ & $98 \cdot 3(0 \cdot 1)$ \\
60 & $97 \cdot 5(0 \cdot 2)$ & $97 \cdot 0(0 \cdot 4)$ & $97 \cdot 1(0 \cdot 3)$ & $97 \cdot 4(0 \cdot 3)$ & $97 \cdot 5(0 \cdot 2)$ & $97 \cdot 5(0 \cdot 3)$ & $98 \cdot 5(0 \cdot 4)$ \\
120 & $96 \cdot 8(0 \cdot 5)$ & $97 \cdot 0(0 \cdot 9)$ & $97 \cdot 0(0 \cdot 2)$ & $91 \cdot 1(0 \cdot 4)$ & $97 \cdot 2(0 \cdot 3)$ & $97 \cdot 3(0 \cdot 4)$ & $98 \cdot 5(0 \cdot 4)$ \\
Maalox: & & & & & & & \\
10 & $93 \cdot 1(0 \cdot 1)$ & $96 \cdot 5(0 \cdot 1)$ & $96 \cdot 6(0 \cdot 1)$ & $94 \cdot 2(0 \cdot 2)$ & $94 \cdot 1(0 \cdot 2)$ & $95 \cdot 6(0 \cdot 1)$ & $96 \cdot 0(0 \cdot 2)$ \\
30 & $92 \cdot 2(0 \cdot 2)$ & $94 \cdot 9(0 \cdot 1)$ & $96 \cdot 0(0 \cdot 1)$ & $94 \cdot 0(0 \cdot 2)$ & $93 \cdot 9(0 \cdot 3)$ & $95 \cdot 2(0 \cdot 2)$ & $95 \cdot 7(0 \cdot 2)$ \\
60 & $90 \cdot 0(0 \cdot 2)$ & $94 \cdot 5(0 \cdot 1)$ & $95 \cdot 3(0 \cdot 3)$ & $93 \cdot 5(0 \cdot 3)$ & $93 \cdot 6(0 \cdot 2)$ & $94 \cdot 8(0 \cdot 2)$ & $95 \cdot 0(0 \cdot 3)$ \\
120 & $85 \cdot 2(0 \cdot 4)$ & $91 \cdot 8(0 \cdot 9)$ & $94 \cdot 8(0 \cdot 3)$ & $93 \cdot 2(0 \cdot 3)$ & $93 \cdot 2(0 \cdot 3)$ & $94 \cdot 1(0 \cdot 2)$ & $94 \cdot 0(0 \cdot 3)$ \\
\hline
\end{tabular}

serum albumin) was added and incubated at $37^{\circ} \mathrm{C}$ for 5 minutes, and $2 \mathrm{ml}$ of $\mathrm{NaCl} 0.9 \%$ was added and then centrifuged at $1000 \mathrm{~g}$ for 5 minutes. The acidity of the solid and liquid phases was measured.

To assess whether the labelling procedure might induce changes in the size of the colloidal particles and the formation of macroaggregates of the antacids, dark field microscopy of the labelled and unlabelled antacids was performed.

PROCEDURE

After an eight hour fast each subject ingested a meal consisting of a one egg omelette sandwich ( $50 \mathrm{~g}$ bread, $50 \mathrm{~g}$ egg, and $5 \mathrm{~g}$ olive oil) and $200 \mathrm{ml}$ of orange juice. The total energy content of the meal was $95 \cdot 7 \mathrm{MJ}$ ( $400 \mathrm{kcal}$ ) (carbohydrate $40 \%$, fat $30 \%$, protein $22 \%) .{ }^{21}$

One hour after the meal each subject ingested $10 \mathrm{ml}$ of one of the two antacids previously labelled with ${ }^{99 m} \mathrm{Tc}$ and was immediately placed in front of a camera detector (large view field camera on line to a standard computer. General Electric Maxi II on line to a PDP 11-34 DigitalGamma-11.). The amount of radioactivity retained in the stomach was recorded in anterior and posterior projections (to calculate geometrical means).

These readings were repeated at six intervals of 15 minutes. During the study subjects could remain seated or walk about in a 5 metre area. All studies were done in the afternoon. Six smokers were not allowed to smoke for eight hours before the study. The study was repeated one week later under the same conditions with the other labelled antacid.

STATISTICAL ANALYSIS

The results corrected for radioactive decay are expressed as a percentage of the initial counts in

TABLE II Antacid capacity of labelled antacids. With continuous stirring $10 \mathrm{ml}$ of $0.15 \mathrm{M} \mathrm{NaCl}, 10 \mathrm{ml}$ of $0.4 \mathrm{M}$ $\mathrm{HCl}$, and $2 \mathrm{ml}$ of antacid (unlabelled or labelled) were added to a flask. Time intervals in seconds to reach fixed $\mathrm{pH}$ were recorded (mean $(S D)$ )

\begin{tabular}{lllll}
\hline & $p H$ & & & \\
\cline { 2 - 5 } & $3 \cdot 4$ & $3 \cdot 5$ & $3 \cdot 6$ & \\
& $(n=5)$ & $(n=5)$ & $(n=5)$ & \\
\hline Magaldrate & $13(1 \cdot 1)$ & $25(1 \cdot 4)$ & $40(2 \cdot 7)$ & Not \\
Mc magaldrate & $13(1 \cdot 0)$ & $25(1 \cdot 5)$ & $39(2 \cdot 8)$ & significant \\
Maalox & $56(3 \cdot 0)$ & $61(3 \cdot 6)$ & $68(4 \cdot 3)$ & Not \\
Mc Maalox & $57(2 \cdot 9)$ & $59(3 \cdot 6)$ & $65(4 \cdot 5)$ & significant \\
\hline
\end{tabular}

TABLE III Mean percentages of antacids retained in the stomachs of 15 healthy male volunteers

\begin{tabular}{|c|c|c|c|c|c|c|}
\hline \multirow[b]{2}{*}{$\begin{array}{l}\text { Time } \\
(\min )\end{array}$} & \multicolumn{3}{|c|}{ Magaldrate } & \multirow[b]{2}{*}{ Mean } & \multicolumn{2}{|c|}{ Maalox } \\
\hline & Mean & $S D$ & $S E$ & & $S D$ & $S E$ \\
\hline $\begin{array}{l}15 \\
30 \\
45 \\
60 \\
75 \\
90\end{array}$ & $\begin{array}{l}91 \cdot 94 \\
82 \cdot 27 \\
70 \cdot 07 \\
58 \cdot 46 \\
48 \cdot 86 \\
41 \cdot 28\end{array}$ & $\begin{array}{r}6 \cdot 43 \\
11 \cdot 32 \\
15 \cdot 71 \\
18 \cdot 59 \\
19 \cdot 25 \\
18 \cdot 12\end{array}$ & $\begin{array}{l}1 \cdot 66 \\
2.92 \\
4.05 \\
4 \cdot 80 \\
4.97 \\
4 \cdot 67\end{array}$ & $\begin{array}{l}85 \cdot 87 \\
69 \cdot 49 \\
55 \cdot 43 \\
43 \cdot 84 \\
34 \cdot 32 \\
28 \cdot 21\end{array}$ & $\begin{array}{r}6 \cdot 23 \\
14 \cdot 02 \\
17 \cdot 42 \\
14 \cdot 37 \\
14 \cdot 13 \\
12 \cdot 37\end{array}$ & $\begin{array}{l}1.61 \\
3.62 \\
4.50 \\
3.71 \\
3.65 \\
3 \cdot 19\end{array}$ \\
\hline
\end{tabular}

the stomach at $15,30,45,60,75$, and 90 minutes. In each subject the half emptying time $(\mathrm{t} 1 / 2)$ was calculated from the regression line of the log counts against time. Results were analysed using the two sample $t$ test to compare mean $t 1 / 2$ values between the two antacids. The comparison of the mean percentages of antacids retained in the stomach was based on the analysis of variance. The statistical package for the social sciences (SPSS/PC) was used.

\section{Results}

LABELLING OF ANTACIDS

The stability of the ${ }^{99 m}$ Tc-pyrophosphate antacids in gastric juice is shown in Table $\mathrm{I}$. The percentage of radioactivity bound to magaldrate was greater than $96 \%$ at a $\mathrm{pH}$ of $1 \cdot 5-7$. The percentage of radioactivity bound to Maalox was slightly less, especially at 120 minutes at $\mathrm{pH} 1.5$. But these results could be considered satisfactory for both antacids.

The antacid capacity of the labelled antacids compared with that of the unlabelled antacids is given in Table II. There were no significant differences between labelled and unlabelled antacids in the time needed to achieve a neutral $\mathrm{pH}$.

Protein binding of both labelled and unlabelled magaldrate and Maalox showed a similar behaviour: mean (SD) labelled magaldrate $98 \cdot 1$ $(0 \cdot 1) \%$, unlabelled magaldrate $98.6 \quad(0 \cdot 1) \%$ $(\mathrm{n}=5$, not significant); labelled Maalox $78 \cdot 5$ $(0.7) \%$, unlabelled Maalox $78.9(0.6) \%(n=5$, not significant).

Dark field microscopy showed no macroaggregates in either labelled or unlabelled antacids, and the particulate size was about $0.5 \mu \mathrm{m}$ for Maalox and 2-7 $\mu \mathrm{m}$ for magaldrate.

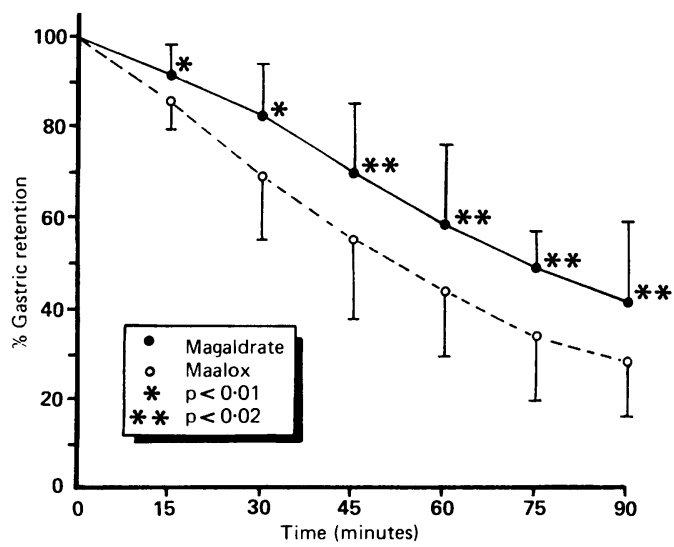

Percentage of antacids retained in the stomach at different time intervals. 


\section{GASTRIC EMPTYING OF ANTACIDS}

The mean (SD) percentages of the antacids retained in the stomach fit a linear model. The $t^{1} / 2$ for magaldrate was $86 \cdot 8(15 \cdot 3)$ minutes and for Maalox $52 \cdot 3(5 \cdot 2)$ minutes $(\mathrm{p}<0 \cdot 05)$.

The mean percentage of retention at the six times studied for each antacid is given in Table III. One hour after ingestion $58.4 \%$ of the magaldrate and $43.8 \%$ of the Maalox were retained in the stomach. After one and a half hours, the mean percentages were $41 \cdot 2 \%$ and $28.2 \%$ respectively. Maalox emptied significantly faster at all times studied $(\mathrm{p}<0.01$ at 15 and 30 minutes, $\mathrm{p}<0.02$ at $45,60,75$, and 90 minutes; Figure).

\section{Discussion}

Some antacids, especially those containing aluminium, delay gastric emptying of both liquids $^{22}$ and solids. ${ }^{23}$ Aluminium ion, made soluble when aluminium hydroxide reacts with the hydrochloric acid in gastric contents, has been shown to inhibit acetylcholine induced contractions of rodent and human gastric smooth muscle. ${ }^{24}$ It must, however, be in contact with the gastric mucosa for one to two hours for aluminium ions to diffuse through to the muscle and inhibit contraction. ${ }^{22}$ Therefore, a prolonged period of antacid retention in the stomach may be considered desirable because rapid gastric emptying of liquid antacids is believed to be a limiting factor in the duration of their neutralising and cytoprotective effects.

Radionuclide imaging techniques are well established for monitoring gastric emptying. ${ }^{2126}$ In studies on gastric emptying of labelled antacids for accurate results it is essential that the isotope remains associated with the components of antacids.

Ideally, the antacid should be radiolabelled with an isotope of one of its components, but none of the elements is currently available as a radioactive isotope for use in humans. In this study labelling was carried out with ${ }^{99 m} \mathrm{Tc}$. The labelled antacids had a satisfactory stability at a wide range of $\mathrm{pH}$ values ( $\mathrm{pH} 1 \cdot 5-7)$. The protein binding capacity of the antacids did not change after labelling, and we were able to show by dark field microscopy that labelling antacids does not lead to the formation of macroaggregates which might show an emptying pattern different from that of the unlabelled antacids. The antacid capacity was similar in labelled and unlabelled samples. ${ }^{113 m}$ In has been used in all studies of gastric emptying of antacids carried out so far. ${ }^{27}{ }^{28}$ Using ${ }^{99 m} \mathrm{~T} \mathrm{c}$, which we have shown to be reliable, has advantages such as better physical properties for accurate detection, less radiation delivered to patients, and lower costs.

The meal given in this study had been evaluated in gastric emptying of solids and liquids in control subjects and under different physiological and pathological conditions. ${ }^{21} 25$ In addition, antacids were administered in the usual form one hour after the meal.

As there are notable differences in the methods used in published studies of gastric emptying of antacids, it is difficult to compare them. Jenkins et al studied emptying four hours after the meal ${ }^{27}$ and May et al 30 minutes after a liquid caloric meal. ${ }^{28}$

In this study at all time intervals the emptying of magaldrate was significantly slower than that of Maalox. This might have been due to the special chemical structure of magaldrate, to its ability to adhere to the stomach wall, or to its different capacity for binding proteins. Thus, in practice magaldrate performs as a solid in so much as gastric emptying is concerned (mean (SD) t1/2 magaldrate $86 \cdot 8(15 \cdot 3)$ minutes; $t 1 / 2$ for solid phase $85 \cdot 3(4 \cdot 5)$ minutes). Theoretically, this slower gastric emptying should provide greater neutralising and cytoprotective effects. But Maalox, with a t1/2 of $52 \cdot 3(5 \cdot 2)$ minutes, shows a rate of emptying similar to that found for a caloric liquid (Clinifeed ISO, Roussel Laboratories, Wembley Park, UK). ${ }^{28}$

${ }^{99 m} \mathrm{Tc}$ labelling of antacids containing $\mathrm{Al}(\mathrm{OH})_{3}$ and $\mathrm{Mg}(\mathrm{OH})_{2}$ is feasible, stability is satisfactory, and gastric emptying of labelled antacids can be monitored by scintigraphic techniques. Therefore, gastric emptying of labelled antacids may be useful in monitoring how long antacids remain in patients' stomachs.

This work was supported in part by grant FISS 89/0083 and in part by Boehringer-Mannheim Laboratories.

1 Peterson WL, Sturdevant RAL, Frank IHD, et al. Healing of duodenal ulcer with antacid regimen. $N$ Engl f Med 1977; 297: $341-5$

2 Ippoliti AF, Sturdevant RAL, Isenberg JI, et al. Cimetidine versus intensive antacid therapy for duodenal ulcer. Gastroenterology 1978; 74: 393-5.

3 Ippoliti AF, Elashoff J, Valenzuela J, et al. Recurrent ulcer after successful treatment with cimetidine or antacids. Gastroenterology 1983; 85: 875-80.

4 Lauritsen K, Bytser P, Hanssen J, Bekker C, Rask Madsen J. Comparison of ranitidine and high dose antacid in the treatment of prepyloric or duodenal ulcer: a double-blind treatment of prepyloric or duodenal ulcer: a double-b
controlled trial. Scand $\mathcal{F}$ Gastroenterol 1985; 20: 123-8.

5 Bianchi Porro G, Parente F, Lazzaroni M, Baroni S, Panza E. Medium-dose antacids versus cimetidine in the short-term treatment of duodenal ulcer. $\mathcal{F}$ Clin Gastroenterol 1986; 8: $141-5$

6 Fordtran JS, Morawski SG, Richardson CT. In vivo and in vitro evaluation of liquid antacids. $N$ Englf $M e d$ 1973; 288: 923-8.

7 Massarat S, Eisennann A. Factors affecting the healing rate of duodenal ulcer and pyloric ulcer with low dose antacid treatment. Gut 1981; 22: 97-102.

8 Bertad A, Rydning A, Aadland E, Kolstad B, Frislid KL, Aaseth J. Controlled clinical trial of duodenal ulcer healing with antacid tablets. Scand 7 Gastroenterol 1982; 17: 953-9.

9 Kumar W, Vij JC, Karol A, Anand BS. Controlled therapeutic trial to determine the optimum dose of antacids in duodenal ulcer. Gut 1984; 24: 1199-202.

10 Blum AL. Stellung der antacids in der modernen ulcustherapie. Dtsch Med Wochenschr 1985; 110: 3-7.

11 Szelenyi I, Postins S, Engler H. Evidence for a functional cytoprotective effect produced by antacids in the rat stomach. Eur 7 Pharmacol 1983; 88: 403-6.

12 Domschke W, Hagel J, Ruppin H, Kaduk B. Antacids and gastric mucosal protection. Scand $\mathcal{f}$ Gastroenterol 1986; 21 gastric mucosal pro.

13 Berstad A, Weberg R. Antacids for peptic ulcer: do we have anything better? Scand f Gastroenterol 1986; 21: 144-9.

14 Hollander D, Tanarwski A, Gergely H. Protection against alcohol-induced gastric mucosal injury by aluminium sulfate. Scand F Gastroenterol 1986; 1 (suppl 125): 151-3.

15 Preclik G, Stange EF, Gerber K, Fetzer G, Horn H, Ditschuneit $\mathbf{H}$. Stimulation of mucosal prostaglandin synthesis in human stomach and duodenum by antacid treatment. Gut 1989; 30: 148-51.

16 Deering TB, Carlson GL, Malagelada JR, Duenes JA, McCall JT. Fate of oral neutralizing antacid and its effects on postprandial gastric secretion and emptying. Gastroenterology 1979; 77: 986-90.

17 Malagelada JR, Carlson GL. Pharmacological basis and clinical use of antacid. In: Holtermüller KH, Malagelada clinical use of antacid. In: Holtermüller $\mathrm{KH}$, Malagelada JR, eds. Advances in ulce
Medica, 1980: 376-405.

18 Holtermüller KH, König U. Safety of antacids. In: Bianchi Porro G, Richardson CT, (eds.) Antacids in peptic ulcer disease. State of the Art. Raven Press: New York, 1988: 41-52.

19 Serna CJ, White JL, Hem SL. Structural survey of carbonatecontaining antacids. F Pharm Sci 1978; 67: 324-7.

20 Guterman LR, Falzone CJ, Wilson GE. Action of hydrochloric acid on aluminium hydroxide-magnesium hydroxid 
gels and magaldrate: quasi-elastic light scattering studies. gels and magaldrate: quasi-

21 Carrió I, Estorch M, Serra-Grima R, et al. Gastric emptying in marathon runners. Gut 1989; 30: 502-5.

22 Hurwitz A, Robinson RG, Vats TS, Whittier FC, Herrin WF. Effects of antacids on gastric emptying. Gastroenterology 1976; 71: 268-73.

23 Marano AR, Caride VJ, Prokop EK, Troncale FJ, McCallum RW. Effect of sucralfate and aluminium hydroxide gel on gastric emptying of solids and liquids. Clin Pharmacol Ther $1985 ; 37: 629-32$

24 Hava $M$, Hurwitz A. The relaxing effect of aluminium and lanthanum on rat and human gastric smooth muscle in vitro. Eur f Pharmacol 1973; 22: 156-61.
25 Calabuig R, Carrió I, Monés J, et al. Gastric emptying after truncal vagotomy and pyloroplasty. Scand $\mathcal{f}$ Gastroentero 1988; 23: 659-64

26 Jian R, Ducrot F, Piedeloup C, Masy JY, Najean Y, Bernier $\mathrm{JJ}$. Measurement of gastric emptying in dyspeptic patients: effect of a new gastrokinetic agent (cisapride). Gut 1985; 26: $352-8$

27 Jenkins JRF, Hardy JG, Wilson CG. Monitoring antacid preparations in the stomach using gamma scintigraphy. Int Pharmacol 1983; 14: 143-8.

28 May HA, Wilson CG, Hardy JG. Monitoring radiolabelled antacid preparations in the stomach. Int f Pharmacol 1984; 19: 169-76. 